\title{
The Effect of Arm Position on Lower Extremity Kinematics during a Single Limb Drop Landing: A Preliminary Study
}

\author{
Cameron Masters ${ }^{1}$, James Johnstone ${ }^{2}$ and Gerwyn Hughes ${ }^{3, *}$ \\ 1 Department of Psychology and Sports Sciences, University of Hertfordshire, AL10 9AB Hatfield, UK; \\ cameronmasters9@yahoo.co.uk \\ 2 The Cambridge Centre for Sport and Exercise Sciences, Anglia Ruskin University, CB1 1PT Cambridge, UK; \\ james.johnstone@anglia.ac.uk \\ 3 Department of Kinesiology, University of San Francisco, San Francisco, CA 94117, USA \\ * Correspondence: ghughes@usfca.edu; Tel.: +1-415-422-6615
}

Academic Editor: Giuseppe Musumeci

Received: 20 May 2016; Accepted: 27 June 2016; Published: 30 June 2016

\begin{abstract}
Anterior cruciate ligament (ACL) injuries occur most commonly during non-contact situations, such as landing from a jump. Arm position has been shown to affect the loading of the lower extremity and therefore alter the potential injury risk. This study aimed to investigate the effect of arm position on lower extremity kinematics during single limb drop landings. Eight recreational American football players performed single limb drop landings on their preferential limb in four different conditions; (1) control (arms free); (2) arms to landing limb side; (3) arms in front of body; and (4) arms away from landing limb side. Kinematics of the hip, knee and ankle were recorded in both the sagittal and frontal planes at initial ground contact and maximum. Results showed that there was a significant decrease in maximum hip flexion and a significant increase in peak dorsiflexion when landing with arms away from the landing-side limb. Since decreased hip flexion and increased ankle dorsiflexion have been proposed to increase the likelihood of ACL injury, it would appear that landing with arms away from the landing-side limb may increase the risk of ACL injury, and therefore athletes should avoid this position when landing from a jump.
\end{abstract}

Keywords: anterior cruciate ligament; landing; kinematics

\section{Introduction}

Between $70 \%$ and $84 \%$ of anterior cruciate ligament (ACL) injuries have been reported to occur in non-contact situations [1] where there is no direct blow to the knee at the time of injury. This includes movements such as landing and change of direction (cutting or pivoting) and occurs most commonly close to initial contact when the limb makes contact with the ground close to full extension and in a valgus position with a planted foot [1-4]. In addition, ACL injuries are reported to occur more commonly during single-limb tasks than during double-limb tasks [4]. The effects of ACL injury can often be debilitating and result in long-term functional impairment including knee instability [5] and changes in motor unit recruitment during low-level contractions [6]. Subsequently, this often causes further damage of the menisci and articular surfaces which reduces knee function and in turn reduces a patient's level of physical activity $[7,8]$.

Whilst the kinetics (joint moments and forces) acting on a joint is likely to provide the most accurate indication of the loading experienced by the passive support structures, in particular the ligaments, the kinematics may also provide some indication of the risk of injury. Bakker et al. [9] examined the effects of sagittal plane kinematics on ACL strain in drop landings using a combined 
in vivo/computational/in vitro methodology. This involved inputting motion capture data into a musculoskeletal computer model of the lower extremities to estimate the forces that cross the knee. These forces were then applied to instrumented cadaver knees while the ACL strain was measured. The results showed that a number of kinematic variables correlated with increased ACL strain, including decreased maximum knee flexion and decreased hip and knee flexion at maximum ground reaction force. A more upright or "stiff" landing movement pattern, characterised by reduced flexion of the hip and knee joints coupled with increased ankle dorsiflexion [1], has been proposed to increase the risk of ACL injury. This may be due to these kinematic factors increasing the ground reaction force and reducing the ability of the hamstring muscles to prevent anterior shear force acting on the proximal end of the tibia [10], which in turn is likely to increase the strain on the ACL [11]. Knee valgus motion, caused by the excessive hip adduction and internal rotation whereby these movements combine to cause the tibia to abduct and the foot to pronate when the foot is fixed to the floor [12], has also been shown to increase the relative load on the ACL [13].

Performing landing movements during sports such as basketball and certain positions in American football (i.e., wide receivers, tight ends, and defensive backs) where players are frequently required to catch a ball means that the arm position is often varied. The position and movement of the arms has been suggested to influence the loading of the lower extremity, which may in turn influence the risk of injury [14]. Despite this, the effect of arm position on landing biomechanics is still largely unclear. Chaudhari et al. [14] investigated valgus knee loading during four $90^{\circ}$ cutting tasks: (1) no arm constraints; (2) holding a football in the plant side arm; (3) holding a football under the cut side arm; (4) holding a lacrosse stick. The results showed that the knee valgus moment was influenced by the arm position whereby holding the ball in the plant foot arm and holding a lacrosse stick increased knee valgus moment relative to the no-arm-constraints condition whereas holding a football under the cut side arm did not change the knee valgus moment relative to the no-arm-constraints condition. These findings suggest that preventing weight from moving over the plant limb through constraining arm movement may increase knee valgus loading, which in turn may increase the risk of ACL injury. However, further evidence is required to validate this theory during different tasks in which ACL injuries frequently occur, such as landing. In addition, little is known regarding the effect arm position has on the kinematics of the lower limb which has been proposed as a risk factor for ACL injury. Therefore, the aim of this study was to examine the effects of arm position on hip, knee and ankle kinematics during single-limb drop landings in recreational American footballers.

\section{Materials and Methods}

\subsection{Participants}

Eight recreational university American football players (age $=20.0 \pm 1.3$ years, body mass $=80.3 \pm 10.7 \mathrm{~kg}$, height $=1.84 \pm 0.05 \mathrm{~m}$ ) gave informed consent to take part in the study. Prior to testing, ethical approval was granted by the University of Hertfordshire Health and Human Sciences Ethics Committee. Inclusion criteria was that the participants were male, aged between 18 and 30 and part of the University of Hertfordshire American Football team with no current knee or back injuries and no knee ligament injuries in the past.

\subsection{Protocol}

Prior to data collection, participants were instructed to perform a standardised 5 min warm-up on the cycle ergometer followed by a set of lower limb dynamic stretches (body weight squats, rotational lunges, side lunges, hamstring walks). Once completed, the participants were given the opportunity to practice single limb drop landings from incremental heights until they were comfortable performing the landing task.

Participants were labelled with 29 retro-reflective markers in accordance with the Helen Hayes marker set with markers placed directly on the skin. Marker locations were as follows: three markers 
on head (top, front and back), right scapula, right and left acromion process, each lateral epicondyle of humerus, between styloid processes of each radius and ulna, anterior superior illiac spines, sacrum, each lateral thigh, each lateral shank, lateral and medial knees, lateral and medial ankles, heels and toes. Markers placed on the lateral and medial ankles and knees were only recorded during static trials and were then removed for all dynamic trials. For the recorded trails, the three-dimensional (3D) coordinates of these markers were recorded using a nine-camera motion analysis system (Motion Analysis Corp., Santa Rosa, CA, USA) sampling at $120 \mathrm{~Hz}$.

Participants were required to perform single limb drop landings on the preferential limb from a $0.42 \mathrm{~m}$ platform in four different conditions: (1) control (arms free); (2) arms positioned at right angles to the body's longitudinal axis towards the side of the landing limb while holding a ball; (3) arms positioned at right angles to the body's longitudinal axis in front of the body while holding a ball; and (4) arms positioned at right angles to the body's longitudinal axis to the side of the non-landing limb while holding a ball (Figure 1). Preferential limb was defined as the limb the participant would choose to kick a football [15]. Each subject completed three repetitions of each landing condition with between 60 and $90 \mathrm{~s}$ rest in between trials.

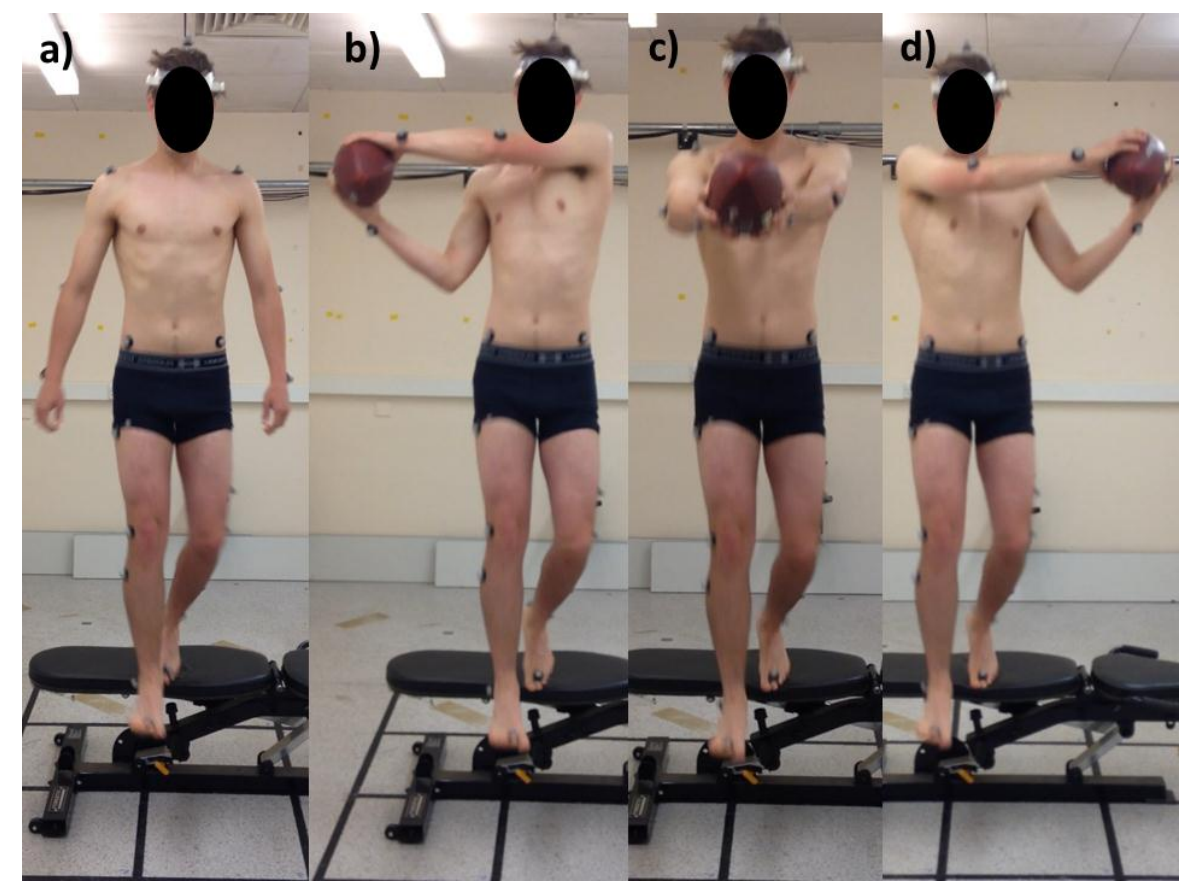

Figure 1. Landing conditions: (a) control; (b) arms to landing limb side; (c) arms in front of body and (d) arms to non-landing limb side.

\subsection{Data Analysis}

Marker trajectories were filtered at $6 \mathrm{~Hz}$ using a fourth-order Butterworth filter. From the location of the three-dimensional coordinates of the markers placed on the body, the measurement of joint angles were determined as the Euler angle of the distal segment reference frame relative to the proximal segment reference plane rotated in the order (1) mediolateral axis; (2) anterioposterior axis; (3) longitudinal axis.

Statistical tests were performed using the computer package IBM SPSS v.23.0. Repeated measures ANOVA determined the effect of arm position on the kinematics of the hip, knee and ankle joints in both the sagittal and frontal planes at initial ground contact and maximum. A priori alpha level was set at 0.05 . 


\section{Results}

\subsection{Initial Ground Contact}

There were no significant effects at initial ground contact for kinematics of the hip, knee and ankle in both the sagittal and frontal planes $(p>0.05)$ (Table 1).

Table 1. Sagittal and frontal plane kinematics at initial contact and maximum during single limb drop landings.

\begin{tabular}{|c|c|c|c|c|c|}
\hline & & Control & Landing Side & In Front & Non-Landing Side \\
\hline Hip flexion $\left(^{\circ}\right)$ & $\begin{array}{l}\text { Initial contact } \\
\text { Maximum }\end{array}$ & $\begin{array}{c}19.1 \pm 9.0 \\
40.0 \pm 13.5\end{array}$ & $\begin{array}{c}16.9 \pm 8.3 \\
37.5 \pm 9.6^{1}\end{array}$ & $\begin{array}{c}14.0 \pm 8.4 \\
33.3 \pm 8.9^{2}\end{array}$ & $\begin{array}{c}14.2 \pm 7.3 \\
29.6 \pm 7.5^{1,2}\end{array}$ \\
\hline $\begin{array}{l}\text { Hip abduction }(-) / \\
\text { adduction }(+)\left(\left(^{\circ}\right)\right.\end{array}$ & $\begin{array}{c}\text { Initial contact } \\
\text { Maximum }\end{array}$ & $\begin{array}{c}-11.9 \pm 5.7 \\
0.4 \pm 7.4\end{array}$ & $\begin{array}{c}-10.0 \pm 4.7 \\
2.1 \pm 7.7\end{array}$ & $\begin{array}{c}-11.2 \pm 6.1 \\
0.9 \pm 6.8\end{array}$ & $\begin{array}{l}-12.1 \pm 5.5 \\
-1.4 \pm 7.9 \\
\end{array}$ \\
\hline Knee flexion $\left(^{\circ}\right)$ & $\begin{array}{l}\text { Initial contact } \\
\text { Maximum }\end{array}$ & $\begin{array}{l}21.4 \pm 5.7 \\
59.0 \pm 7.5\end{array}$ & $\begin{array}{l}20.7 \pm 6.0 \\
58.7 \pm 6.4\end{array}$ & $\begin{array}{l}21.0 \pm 4.4 \\
59.1 \pm 5.5\end{array}$ & $\begin{array}{l}20.8 \pm 3.3 \\
58.5 \pm 6.1\end{array}$ \\
\hline $\begin{array}{c}\text { Knee valgus }(-) / \\
\text { varus }(+)\left({ }^{\circ}\right)\end{array}$ & $\begin{array}{c}\text { Initial contact } \\
\text { Maximum }\end{array}$ & $\begin{array}{c}5.0 \pm 5.8 \\
-21.3 \pm 12.3\end{array}$ & $\begin{array}{c}5.8 \pm 4.1 \\
-25.3 \pm 12.8\end{array}$ & $\begin{array}{c}5.2 \pm 3.7 \\
-24.3 \pm 13.4\end{array}$ & $\begin{array}{c}3.9 \pm 4.1 \\
-20.7 \pm 11.1\end{array}$ \\
\hline $\begin{array}{l}\text { Ankle plantar }(-) / \\
\text { dorsiflexion }(+)\left(\left(^{\circ}\right)\right.\end{array}$ & $\begin{array}{c}\text { Initial contact } \\
\text { Maximum }\end{array}$ & $\begin{array}{c}-40.1 \pm 8.3 \\
6.9 \pm 4.6\end{array}$ & $\begin{array}{l}-41.4 \pm 11.0 \\
5.6 \pm 3.1^{3,4}\end{array}$ & $\begin{array}{l}-41.0 \pm 7.1 \\
6.9 \pm 3.1^{3,5}\end{array}$ & $\begin{array}{l}-38.3 \pm 9.6 \\
8.0 \pm 3.4 \\
\end{array}$ \\
\hline Ankle inversion $\left(^{\circ}\right)$ & $\begin{array}{l}\text { Initial contact } \\
\text { Maximum }\end{array}$ & $\begin{array}{l}29.6 \pm 15.8 \\
10.7 \pm 19.6\end{array}$ & $\begin{array}{c}24.6 \pm 4.9 \\
5.0 \pm 5.7\end{array}$ & $\begin{array}{c}26.0 \pm 4.7 \\
5.4 \pm 5.3\end{array}$ & $\begin{array}{c}24.3 \pm 6.1 \\
-21.2 \pm 10.1\end{array}$ \\
\hline
\end{tabular}

\subsection{Maximum Angles}

There was a significant effect and large effect size for the arm position in the maximum hip flexion angle $\left(\mathrm{F}_{(3,5)}=7.13, p=0.03, \eta_{\mathrm{p}}{ }^{2}=0.81\right)$. Post-hoc tests revealed maximum hip flexion to be significantly lower when landing with the arms towards the non-landing limb side compared to when landing with arms toward the landing limb $(p=0.044)$ and in front $(p=0.014)$ (Table 1$)$.

There was a significant effect and large effect size for arm position in the peak dorsiflexion angle $\left(\mathrm{F}_{(3,5)}=24.7, p=0.002, \eta_{\mathrm{p}}{ }^{2}=0.94\right)$. Post-hoc tests indicated ankle dorsiflexion was significantly reduced when landing with arms towards the landing limb side as compared to when landing with arms towards the non-landing limb side $(p=0.004)$ and in front $(p=0.000)$. Furthermore, post-hoc test revealed that ankle dorsiflexion was significantly reduced when landing with arms in front of the body than when arms were located towards the non-landing limb side $(p=0.006)$.

There were no significant effects for maximum knee flexion angle or maximum angles of the hip, knee and ankles in the frontal plane $(p>0.05)$.

\section{Discussion}

The main findings of the study are that landing with the arms away from the landing limb caused a decrease in maximum hip flexion and an increase in maximum ankle dorsiflexion when compared to both landing with the arms towards the landing-side limb and arms in front of the body. Both reduced hip flexion and increased ankle dorsiflexion have been proposed as risk factors for ACL injury [1]; therefore, this suggests that landing with arms away from the landing limb may result in increased risk of ACL injury.

There was no significant effect for arm position in any lower limb kinematic variable at initial ground contact and there was no significant effect for arm position on the knee kinematics in either the frontal or sagittal planes. Previous research has shown that ACL injury frequently occurs close to initial contact with the ground where the knee is close to full extension and in a valgus position $[4,16]$. The current study shows that the arm position has little effect on these kinematic variables and therefore may not increase injury risk through altering the kinematics of the knee itself. Previous research has 
shown that moving the arms away from the body and restricting the arms by not allowing them to aid in maintaining balance when performing cutting movements influences the valgus loading about the knee [14]. Whilst the current study showed no effect of arm position on the kinematics of the knee in the frontal plane, movement of the knee alone does not determine it's loading since the loading of any joint is influenced by the movement and loading of other joints within the kinetic chain [17]. Therefore, it would appear that the kinematics of the hip and ankle in the sagittal plane may play a crucial role in determining the effect of arm position on knee loading during landing/cutting.

From the results it has been shown that there is a decrease in maximum hip flexion when landing with arms positioned away from the landing limb. By landing with arms towards the landing limb, which shifts the body's center of mass towards the landing leg and therefore over their base of support, participants would likely be in a more stable position during the landing. This would allow the participants to attenuate the impact forces during landing from a more stable base and therefore utilize a greater range of motion of the hip joint. In contrast, landing with arms away from the landing limb, which would move the center of mass away from the base of support, may create a less stable landing position whereby participants were less able to attenuate the impact forces during landing using the hip joint and instead were required to adopt greater ankle dorsiflexion. Furthermore, if the center of mass of the upper body is located over the landing limb (i.e., landing with arms towards landing limb), the moment acting about the hip joint center due to the upper body would be reduced due to a reduction in the moment arm of the upper body's weight. This would result in a reduced requirement on the muscles of the hip and thigh to maintain the body in an upright position, which instead would allow for a greater proportion of the muscles' force-producing capacity to be directed towards attenuating the impact force of landing. Lastly, in accordance with Newton's third law of motion, rotating the arms and trunk towards the landing limb would likely cause and counteract the internal rotation moment at the hip. This would cause a pre-stretch of the external rotator muscles of the hip in resisting this internal rotation moment and may therefore place these muscles in a more effective state for force production.

When landing with a decrease in hip flexion, there tends to be an emphasis on the use of knee extensors (quadriceps) instead of the hip extensors (hamstrings and gluteus maximus) to attenuate the ground reaction forces [10]. Since the quadriceps produce an anteriorly directed shear force on the proximal tibia, which contributes to ACL loading, whereas the hamstrings produce a posteriorly directed shear force on the proximal tibia, which protects the ACL, this finding could be of particular importance. It has previously been reported that lack of knee flexion is a risk factor for ACL injury [18]; however, the results of the present study showed no significant effect for the arm position on the kinematics of the knee in the sagittal plane. Previous research has proposed that reduced hip flexion tends to occur in combination with reduced knee flexion [19], which has led some studies to couple these joints in the sagittal plane [11]. The present study contradicts these suggestions since the arm position was found to alter hip flexion but not knee flexion.

From the results there was an increase in maximum ankle dorsiflexion during landing when the arms were positioned away from the landing limb compared to when the arms were held towards the landing limb or in front of the body. Landing with an increase in dorsiflexion reduces the ability of the gastrocnemius-soleus complex to absorb the ground reaction forces, which in turn means that more of that force is transmitted along to the knee joint [20]. This may in turn place the passive support structures of the knee under greater loading.

The practical implications of the current study are that coaches should train their athletes to try to avoid landing on one limb with arms positioned away from the landing limb since this has been shown to alter the landing kinematics whereby players may be at increased risk of ACL injury. These situations can commonly arise when a receiver is attempting to catch a misdirected pass, and whilst it may be difficult to adjust lower limb kinematics during movement itself, training players to land on the leg nearest to the ball and then move their arms towards the landing leg side once the ball has been caught may allow athletes to recognize the movements which may place their lower limb at 
risk of injury and reduce the stresses placed on the joints. If, however, athletes are forced to land with arms positioned away from the landing limb, they should attempt to avoid excessive dorsiflexion and actively flex their hip in an attempt to minimise ACL injury risk.

A limitation of this study may have been the training history of the athletes. Since participants were recreational American football players, there was a range of athletic ability; therefore, some participants may have been more experienced in performing landing manoeuvres and as a result may have been better prepared to land in a way to reduce the risk of lower extremity injury than others. That said, participants were given ample practice to rehearse the landing tasks prior to data collection. Another limitation of this study is the relatively small sample size tested. However, the findings of this study do suggest that future research in the area is warranted to fully elucidate the relationship between arm position during landing/cutting and lower limb biomechanics. In particular, whilst lower limb kinematics do provide an indication of the risk of ACL injury, they do not measure the loading acting on the joints directly; therefore, research should examine the effect of arm position on the kinetics of the lower limb during movements in which ACL injury is common.

\section{Conclusions}

In summary, the results of the study show that arm position does have an effect on lower extremity landing kinematics whereby landing with arms away from the landing limb was shown to decrease hip flexion and increase ankle dorsiflexion. This may be due to a reduction in stability when landing with the arms away from the landing limb, whereby the body's center of mass is shifted away from the base of support and therefore is in a position where the body is less able to attenuate the impact of landing through utilizing hip flexion and instead must increase ankle dorsiflexion in order to maintain balance. Both reduced hip flexion and increased ankle dorsiflexion have been proposed to increase ACL injury risk; therefore, it is recommended that coaches train their athletes to avoid landing with arms away from the landing limb. It should be noted, however, that this is a preliminary study and therefore further research is required to validate the findings in a wider population.

Acknowledgments: No sources of funding were received in support of this research.

Author Contributions: Cameron Masters and Gerwyn Hughes conceived and designed the experiments; Cameron Masters performed the experiments; Cameron Masters analyzed the data; Gerwyn Hughes and James Johnstone performed the statistical analysis; Gerwyn Hughes, Cameron Masters and James Johnstone wrote the paper.

Conflicts of Interest: The authors declare no conflict of interest.

\section{Abbreviations}

The following abbreviations are used in this manuscript:

$\begin{array}{ll}\text { ACL } & \text { Anterior cruciate ligament }\end{array}$

ANOVA Analysis of variance

\section{References}

1. Alentorn-Geli, E.; Myer, G.D.; Silvers, H.J.; Samitier, G.; Romero, D.; Lázaro-Haro, C.; Cugat, R. Prevention of non-contact anterior cruciate ligament injuries in soccer players. Part 1: Mechanisms of injury and underlying risk factors. Knee Surg. Sports Traumatol. Arthrosc. 2009, 17, 705-729. [CrossRef] [PubMed]

2. Griffin, L.Y.; Agel, J.; Albohm, M.J.; Arendt, E.A.; Dick, R.W.; Garrett, W.E.; Garrick, J.G.; Hewett, T.E.; Huston, L.; Ireland, M.L.; et al. Noncontact anterior cruciate ligament injuries: Risk factors and prevention strategy. J. Am. Acad. Orthop. Surg. 2000, 8, 141-150. [CrossRef] [PubMed]

3. Hewett, T.E.; Myer, G.D.; Ford, K.R.; Heidt, R.S.; Colosimo, A.J.; McLean, S.G.; van deer Bogert, A.J.; Succop, P. Biomechanical measures of neuromuscular control and valgus loading of the knee predict anterior cruciate ligament injury risk in female athletes: A prospective study. Am. J. Sports Med. 2005, 33, 492-501. [CrossRef] [PubMed] 
4. Olsen, O.E.; Mykelbust, G.; Engebretsen, L.; Bahr, R. Injury mechanisms for anterior cruciate ligament injuries in team handball: A systematic video analysis. Am. J. Sports Med. 2004, 32, 1002-1012. [CrossRef] [PubMed]

5. Abulhasan, J.F.; Snow, M.D.; Anley, C.M.; Bakhsh, M.M.; Grey, M.J. An extensive evaluation of different knee stability assessment measures: A systematic review. J. Funct. Morphol. Kinesiol. 2016, 1, 209-229. [CrossRef]

6. Beretta-Piccoli, M.; Schneebeli, A.; Egloff, M.; Cescon, C.; Clijsen, R.; Togninalli, D.; Barbero, M. Myoelectric manifestations of fatigue after ACL reconstruction: A cross-sectional study after postoperative rehabilitation. J. Funct. Morphol. Kinesiol. 2016, 1, 193-199. [CrossRef]

7. Irvine, L.B.; Glasgow, M.M. The natural history of the meniscus in the anterior cruciate insufficiency. J. Bone Jt. Surg. 1992, 74A, 403-405.

8. Smith, B.A.; Livesay, G.A.; Woo, S.L. Biology and biomechanics of the anterior cruciate ligament. Clin. Sports Med. 1988, 12, 637-666.

9. Bakker, R.; Tomescu, S.; Brenneman, E.; Hangalur, G.; Laing, A.; Chandrashekar, N. The effect of sagittal plane mechanics on ACL strain during jump landing. J. Orthop. Res. 2016, 23, 64. [CrossRef] [PubMed]

10. Pollard, C.D.; Sigward, S.M.; Powers, C.M. Limited hip and knee flexion during landing is associated with increased frontal plane knee motion and moments. Clin. Biomech. 2010, 25, 142-146. [CrossRef] [PubMed]

11. Blackburn, J.T.; Padua, D.A. Sagittal-plane trunk position, landing forces, and quadriceps electromyographic activity. J. Athl. Train. 2009, 44, 174-179. [CrossRef] [PubMed]

12. Powers, C.M. The influence of abnormal hip mechanics on knee injury: A biomechanical perspective. J. Orthop. Sports Phys. Ther. 2010, 40, 42-51. [CrossRef] [PubMed]

13. Russell, K.A.; Palmieri, R.M.; Zinder, S.M.; Ingersoll, C.D. Sex differences in valgus knee angle during a single-leg drop jump. J. Athl. Train. 2006, 41, 166-171. [PubMed]

14. Chaudhari, A.M.; Hearn, B.K.; Andriacchi, T.P. Sport-dependent variations in arm position during single-limb landing influence knee loading: Implications for anterior cruciate ligament injury. Am. J. Sports Med. 2005, 33, 824-830. [CrossRef] [PubMed]

15. Maulder, P.; Cronin, J. Horizontal and vertical jump assessment: Reliability, symmetry, discriminative and predictive ability. Phys. Ther. Sport 2005, 6, 74-82. [CrossRef]

16. Boden, B.P.; Dean, G.S.; Feagin, J.A.; Garrett, W.E. Mechanisms of anterior cruciate ligament injury. Orthopedics 2000, 23, 573-578. [PubMed]

17. Watkins, J. Structure and Function of the Musculoskeletal System; Human Kinetics: Champaign, IL, USA, 1999; p. 330.

18. Kirkendall, D.T.; Garrett, W.E. The anterior cruciate ligament enigma: Injury mechanisms and prevention. Clin. Orthop. Res. 2000, 372, 64-68. [CrossRef]

19. Decker, M.J.; Torry, M.R.; Wyland, D.J.; Sterett, W.I.; Steadman, R.J. Gender differences in lower extremity kinematics, kinetics and energy absorption during landing. Clin. Biomech. 2003, 18, 662-669. [CrossRef]

20. Boden, B.P.; Torg, J.S.; Knowles, S.B.; Hewett, T.E. Video analysis of anterior cruciate ligament injury abnormalities in hip and ankle kinematics. Am. J. Sports Med. 2009, 37, 252-259. [CrossRef] [PubMed]

(C) 2016 by the authors; licensee MDPI, Basel, Switzerland. This article is an open access article distributed under the terms and conditions of the Creative Commons Attribution (CC-BY) license (http://creativecommons.org/licenses/by/4.0/). 